\title{
Adolescente "infrator": Pensares e fazeres no Rio Grande do Norte dos governos militares ao ECA
}

Carmem Plácida Sousa Cavalcante. Faculdade de Excelência Educacional do Rio Grande do Norte. Herculano Ricardo Campos. Universidade Federal do Rio Grande do Norte.

\section{Resumo}

O objetivo é analisar registros da imprensa escrita do Rio Grande do Norte de iniciativas do poder público e manifestações de seus representantes sobre adolescente pobre, em conflito com a lei. Sintetiza-se quadro nacional das políticas na área e focase realidade social e contexto institucional da capital, Natal, melhor atendida pela mídia, entre a implementação da Fundação Nacional do Bem Estar do Menor, em 1964, e a Constituição de 1988. Revela-se a mobilização de representantes dos governos, do judiciário, do ministério público e das polícias, para atender demandas sociais de contenção dos "infratores", suas ações e proposições e suas opiniões sobre o tema. Em geral, as concepções sintonizavam com as iniciativas institucionais, marcadas pela repressão e discriminação, inclusive na nomenclatura usada para designar o adolescente. Analisado com base no materialismo histórico-dialético e na psicologia histórico-cultural, o material revela sintonia do quadro local com o nacional, das condições históricas com as concepções emitidas.

Palavras-chave: adolescente infrator; mídia impressa; políticas públicas; repressão.

\begin{abstract}
Juvenile "offender": Reflections and practices in Rio Grande do Norte from military governments to ECA. Analysis are made of the written press of the Rio Grande do Norte of initiatives of the public power and manifestations of its representatives on the poor juvenile, in conflict with the law. Synthesize a national framework of policies in the area and focuses on the social reality and institutional context of the capital, Natal, best covered by media, between an implementation of the National Underage Welfare Foundation in 1964 and the 1988 Constitution. It reveals the mobilization of government representatives, judiciary, public prosecutor, and police, to meet social demands of containment of "offenders", their actions, propositions and opinions on the subject. In general, conceptions attuned to institutional initiatives were marked by repression and discrimination, including the nomenclature used to designate the juvenile. Analyzed based on dialectical and historical materialism and historical-cultural psychology, data reveals a connection between the local and the national framework, from the historical conditions to the conceptions expressed.
\end{abstract}

Keywords: juvenile offender; written press; public policy; repression.

\section{Resumen}

Adolescente "infractor": Pensamientos y prácticas en el Rio Grande do Norte de los gobiernos militares al ECA. Se analiza registros de la prensa escrita del Rio Grande do Norte sobre iniciativas gubernamentales y demostraciones de sus representantes acerca del adolescente pobre en conflicto con la ley. Se resume el marco nacional de políticas en el área, centrandose en la realidad social e institucional del marco de la capital, Natal, mejor servida por los medios de comunicación, entre la aplicación de la Obra Social de la Fundación Nacional de la Infancia (1964) y la Constitución (1988). Se destaca la movilización de los representantes de los gobiernos, del poder judicial, de los fiscales y los policías para satisfacer demandas sociales de contención de los "delincuentes". Desde la perspectiva materialista histórico-dialéctica y de la psicología histórico-cultural, el material revela la relación del contexto local con las condiciones nacionales y de las condiciones históricas con las concepciones emitidas.

Palabras clave: adolescente infractor; medios impresos; políticas públicas; represión. 
A literatura é pródiga em registros que apontam as estratégias de enfrentamento do estado de coisas relativo à infância e adolescência pobres. Muito embora empregadas por setores dominantes da sociedade brasileira desde a época do Império, somente em 1927 se conformou uma política pública para a área, cujos marcos foram o Código de Menores, o aparato jurídico-legal e o sistema de atendimento. Orientada pela Doutrina do Direito do Menor, caracterizava-se pela discriminação entre crianças e menores, pela ideologia higienista e pelo caráter repressivo e encarcerador.

Essa política somente foi extinta em março de 1964, logo no início do golpe civil-militar instaurado no país. No seu lugar, sob a Doutrina da Segurança Nacional, foi implementada a Política Nacional do Bem Estar do Menor - PNABEM, efetivada pela Fundação Nacional do Bem Estar do Menor - FUNABEM - e seus braços estaduais, as Fundações Estaduais do Bem Estar do Menor - FEBEM's. A elas, cabia encarcerar os 'menores' encontrados perambulando, os 'infratores', etc. Em 1979, quando as críticas e a mobilização da sociedade civil organizada, associadas às dificuldades conjunturais do capitalismo, forçaram a distensão do regime militar, a PNABEM se manteve e um novo Código de Menores foi elaborado, sob a Doutrina da Situação Irregular.

A PNABEM somente foi substituída em1988, com a promulgação da atual Constituição e a definição de nova política para a infância e a adolescência, expressa no Estatuto da Criança e do Adolescente. O ECA rompeu com a perspectiva tutelar, até então marco das políticas para o setor, expressa na discriminação entre crianças e menores. Esta perspectiva também se estendia às diferenças de classes sociais, expressa no higienismo, na repressão e encarceramento de crianças e adolescentes pobres. O Estatuto enfatiza que crianças e adolescentes são sujeitos de direitos, em relação aos quais se deve considerar seu peculiar estágio de desenvolvimento, sendo-Ihes garantida prioridade absoluta no atendimento.

Tendo em vista o adolescente em conflito com a lei, o presente estudo é fruto de pesquisa histórica cujas fontes foram dois importantes jornais publicados no estado do Rio Grande do Norte, quais sejam "A República" e "Tribuna do Norte". Seu objetivo foi resgatar as concepções e as iniciativas do poder público veiculadas pela mídia impressa a respeito desses adolescentes, em Natal, no período de 1964 a 1988. Contextualiza-se a Política do Direito do Menor na era Vargas, que a ela imprimiu concepção ideológica positivista, higienista e autoritária. Mostra-se brevemente como essa diretriz sobrexistiu até a promulgação do ECA, tanto entre 1964 e 1979, com a PNABEM sob a Doutrina de Segurança Nacional, quanto entre 1979 e 1988, sob a Doutrina da Situação Irregular. Finaliza-se apresentando os dados da pesquisa e a sua análise.

Do "Problema de Conduta Social" à "Conduta Antissocial" do "Menor": Nada Muda

Uma característica do Estado, na Era Vargas, iniciada em1930, era a combinação de medidas assistenciais com repressão e ações corporativas. Por exemplo, na esteira do apoio ao cultivo do café (Aggio, Barbosa, \& Coelho, 2002) e, em face do crescimento do setor agrário, em 1932, os empresários pressionaram e aprovaram uma alteração no Código de Menores de 1927. Com isso, foi eliminada a proibição para o trabalho antes dos 14 anos de idade, e legalizada a exploração de crianças (Faleiros, 2011; Passeti, 2009). Tal modificação somente foi revogada em 1943, com a Consolidação das Leis do Trabalho - CLT -, sendo adotada a permissão para o trabalho entre 14 e 18 anos de idade, exercido na condição de aprendizado.

Em abril de 1935, valendo-se da complexa conjuntura mundial, às portas da Segunda Grande Guerra, Getúlio dá um golpe de Estado. Segundo ele, "a estratégia do governo é de privilegiar, ao mesmo tempo, a preservação da raça, a manutenção da ordem e o progresso da nação e do país" (Faleiros, 2011, p. 53). Nesta direção, foi aperfeiçoada a política instituída em 1927, sendo criado, em 1941, o Serviço Nacional de Assistência aos Menores - SAM -, para cuidar da assistência ao "menor" abandonado e ao "menor" infrator (Marcílio, 2006) - mais tarde chamados carenciados e de conduta antissocial, respectivamente. A intenção era "eliminar o perigo das ruas", identificado nesses adolescentes (Faleiros, 2011).

A criança ou adolescente, considerado socialmente integrado, precisaria ser membro de uma família "organizada", trabalhar, estudar e consumir (Passeti, 1987). Desconsiderava-se que a família 'desorganizada' era fruto da segregação capitalista aos membros das classes mais necessitadas, que compunham uma massa disforme, carente, desqualificada, a perambular pelas ruas. O SAM representou a atenção do Estado aos filhos dessa massa, caracterizando-se por maus tratos, violência física e psicológica, uso exagerado de psicotrópicos, "adestramento" forçado, cirurgias indevidas (Brasil, 1984; Gomide, 1990). As críticas ao modelo de atendimento do SAM atravessaram os 
governos de Getúlio, de Juscelino Kubitschek e de João Goulart, desembocando nos governos militares, iniciados em março de 1964.

Em 20 de novembro de 1964, foi aprovado o projeto de lei 1712 , depois Lei $n^{\circ} 4513$, de $1^{\circ}$ de dezembro do mesmo ano (Brasil, 1976). Ao tempo em que extinguia o SAM, era criada a FUNABEM e eram fixadas as diretrizes da Política Nacional do Bem Estar do Menor. Esta se fazia implementar por meio das Fundações Estaduais, as FEBEM's, que viriam a sofrer críticas semelhantes às anteriormente dirigidas ao SAM.

Referência teórica da diretriz adotada para o enfrentamento da marginalização na perspectiva menorista, Liborni Siqueira (1979, p.32) defende que, sejam suas causas "ambientais ou hereditárias, adquiridas ou congênitas, desde que afastem o 'menor' de sua normalidade física, mental e social, o tratamento é indispensável; contudo, esta medicina pedagógica antes de ser corretiva, será preventiva". Neste sentido, a nova política contemplava as linhas preventiva e socioterapêutica. A primeira tratava de projetos e programas comunitários visando prevenir a marginalização, e a linha terapêutica se ocupava da atenção à criança e ao adolescente em "situação irregular" (Brasil, 1976).

Na linha terapêutica, eram visados: o atendimento às necessidades mais básicas, explicitadas pela Declaração dos Direitos da Criança, com vistas à realidade nacional; o estabelecimento de uma perspectiva comportamental de um quadro de vida, tendo em vista os princípios nos quais prevaleça o condicionamento positivo; uma educação que dê condições à criança e ao adolescente de vivenciar novos valores éticos, sociais e culturais; uma formação profissionalizante que possibilite a efetivação de uma integração real à sociedade (Brasil, 1976).

Ao tratar da marginalização de crianças e adolescentes pobres, muitas vezes, se esquece que parcela significativa das suas vidas é vivida nas ruas, à mercê das suas lideranças e das suas regras, sem o amparo de família ou da escola. $\mathrm{O}$ aprendizado direto e vivo com o mundo ao seu redor possibilita o encontro com a marginalização (Gomide, 1990). Os reflexos de tal processo são, em geral, a pobreza, a quebra constante de valores e padrões de comportamento cultural, o alto índice de natalidade indesejada, a transgressão da lei (Brasil, 1976). A marginalidade, portanto, deve ser estudada como uma consequência das tendências que o modo de produção capitalista configura, restringindo para uma minoria a possibilidade de acesso aos bens gerados pelo sistema (Schneider, 1987).

O modo de agir do Estado de Bem Estar Social, no Brasil, criava uma espécie de cinturão longo e vicioso de desigualdade social e abstinência financeira naqueles que deveriam estar protegidos. A marginalização de crianças e de adolescentes pobres, expulsos ou compelidos à fuga do ambiente familiar, configura aspecto e manifestação desse processo (Lessa, 2013). Curiosamente, as estratégias de sobrevivência dos que "erram" as cidades país afora no capitalismo periférico, procedendo à perversa ocupação de ruas, praças e calçadas (Sales, 2007), só requerem atenção quando lesivas ao patrimônio público ou privado, e assim, judicializadas.

Nas FEBEM's, a terapêutica começava pela triagem: o adolescente era ouvido pelo Juizado de Menores e, depois, encaminhado para estudo, diagnóstico e indicação de tratamento, no Setor de Estudos e Orientação do Centro de Recepção e Triagem - CRT. O objetivo era caracterizar o tipo e o estágio de marginalização em que se encontrava, para o quê médicos, psiquiatras, psicólogos, assistentes sociais, pedagogos, realizavam exames e entrevistas individuais. Após o diagnóstico, de acordo com a indicação da equipe e com a decisão do juiz, o adolescente recebia um dos três encaminhamentos: voltar ao lar, sob liberdade vigiada; ser internado em estabelecimento educacional comum; ser internado em estabelecimento de "reeducação" (Brasil, 1984).

De acordo com a PNABEM, as unidades para os que se encontravam na prática de atos infracionais desenvolveriam um processo específico de "reeducação", procurando atingir todas as dimensões da sua estrutura subjetiva e social, na tentativa de (re)organizar seu comportamento. O pressuposto era que, através de uma tomada de consciência de si mesmo, de seus sentimentos e suas emoções, o adolescente se "ressocializaria", na condição mais ampla possível (Brasil, 1976).

Por outro lado, na esteira do pensamento de Martins (1997), entende-se que adolescentes em conflito com a lei não se encontram fora da sociedade, devendo a ela voltarem, desde que se submetam aos parâmetros do estatuto jurídico em vigor. Ao contrário, estão socialmente incluídos, cumprem uma função na produção do sistema vigente, muito embora essa 
inclusão seja "precária e instável, marginal". Mediada por tais experiências, sua lógica de compreensão e de ação sobre o mundo tende a reproduzir essa construção social, essa socialização. Logo, não basta uma legislação avançada, pois, por melhor que ajude a lidar com o fato consumado da transgressão, não transforma as condições sociais que a possibilitam (Francischini \& Campos, 2005).

Passado o auge da repressão no Brasil, quando o capitalismo mundial às voltas com a crise do petróleo já não tinha condições de financiar as ditaduras no cone sul, os militares já não eram um bloco unido e nem contavam com o apoio amplo da sociedade, e a Doutrina da Segurança Nacional sofre significativa retração. Nesse contexto, em 1979, a PNABEM é reorientada sob a Doutrina da Situação Irregular, e um novo Código de Menores é editado.

De acordo com Cavallieri (1976), o "Direito do Menor" consistia em um conjunto de normas jurídicas relativas à definição da situação irregular de "adolescentes de conduta antissocial". Tratava-se de "um estado de patologia jurídico-social abordado por normas jurídicas, através de definição, tratamento e prevenção" (p. 9). Assim, o Sistema de Atendimento ao Menor de Conduta Antissocial visava superar o processo de marginalização através de uma proposta pedagógica que mobilizasse educandos, educadores e os aparelhos próprios do Estado. Por isso, a PNABEM tinha sido elaborada, instruída e institucionalizada como política setorial, articulada às demais políticas, marcada por ações supletivas, compensatórias e reparadoras (Brasil, 1984).

A estratégia da segurança nacional através do encarceramento, inclusive de crianças e adolescentes, se tornou objeto de denúncias por amplos setores da sociedade. Assim, o arcabouço ideológico do novo Código e a concepção operacional da Política visavam se adequar à nova conjuntura político-institucional do País, bem como objetivavam responder às críticas sobre o tratamento dispensado aos 'adolescentes infratores', agora pelas FEBEM's. Contudo, permaneceram as práticas autoritárias e discriminatórias, norteadas pelas mesmas concepções de criminalização da pobreza e inclusão perversa. Era a forma como esse estado de coisas aparecia na mídia impressa do período, em Natal, dados que se buscou identificar na pesquisa.

\section{A pesquisa}

Tratou-se de pesquisa documental, cujas fontes foram os jornais "A República" e "Tribuna do Norte", escolhidos em face da sua grande circulação no Rio Grande do Norte, entre 1964 e 1988, período aqui estudado. Tendo em vista ter sua veiculação suspensa no final dos anos 1980 e não dispor de acervo próprio, o acervo do jornal "A República" foi pesquisado no Arquivo Público do Estado, enquanto o da "Tribuna do Norte" foi pesquisado no Laboratório de Imagens do Departamento de História da Universidade Federal do Rio Grande do Norte - LABIM -, onde estava sendo digitalizado.

No Arquivo Público, a pesquisa foi realizada manualmente, folheando-se cada página de cada edição diária - segunda a sexta-feira - e lendo-se os títulos de cada notícia, procurando as que diziam respeito aos 'adolescentes infratores', à política de atendimento ou temas afins. Aquelas consideradas relevantes eram fotografadas, digitalizadas e armazenadas em pasta virtual, sendo depois submetidas ao ABBYY Fine Reader, um software que converte arquivos JPEG (fotos) em PDF pesquisável. Como o jornal "A República" não circulou entre 1961 e 1971, as informações colhidas datam de março de 1972 até dezembro de 1979.

As notícias dos períodos entre 1964 e 1971 e entre 1972 e 1979 são provenientes do acervo da "Tribuna do Norte", que foi pesquisado no Laboratório de Imagens (LABIM), onde estava sendo digitalizado. Para melhor conhecimento, o Laboratório de Imagens foi criado em 2011 e consiste num projeto vinculado ao Departamento de História da Universidade Federal do Rio Grande do Norte, sendo especializado na captura de imagens de livros, jornais, mapas, fotografias e outros tipos de documentos relacionados à História do Rio Grande do Norte.

Continuando, para a pesquisa digital se adotou como indexadores: MENOR; PIVETE; FEBEM; FUNABEM; FUNBERN. Muito embora se tenha trabalhado inicialmente com os indexadores "criança", "adolescente", "infância", "adolescência", "jovem", "juventude", eles não apontaram para notícias que tratavam do tema do "adolescente infrator". Os dados coletados foram organizados e sistematizadas em sentido cronológico, de 1964 a 1988.

\section{Os Registros da Imprensa}

O primeiro registro encontrado é de quatro de novembro de 1968, em que consta que a Organização Judiciária do Estado do $\mathrm{RN}$ informou a respeito de anteprojeto, elaborado por uma comissão de desembargadores, que previa a criação de uma "Vara de Menores" na Comarca de Natal, para assuntos referentes ao problema que circundava as ruas da cidade. Até então, 
as diligências referentes a questões da infância e da adolescência em situação de risco eram encaminhadas para a Vara de Família.

Em que pese desde setembro de 1951 já se encontrar em funcionamento, o Instituto Estevam Machado (IEM), criado pela Arquidiocese de Natal, com vistas a buscar a recuperação de "menores delinquentes", também, por volta de 1968, se registra proposta do governo do estado para reforma da Casa de Detenção, a fim de transformá-la em um Centro de Recepção e Triagem de crianças e adolescentes - CRT. As instalações da Casa de Detenção se encontravam em péssimo estado, depois que o sistema penitenciário transferiu os presos para o Sistema Penitenciário João Chaves. A pressão social para que o estado atentasse para os "delinquentes" decorria do fato de que, até então, a tônica era o atendimento às crianças e adolescentes pobres.

No início da década de 1970, o Departamento de Serviço Social do Estado - DSSE - e a organização judiciária revelavam grande preocupação com os frequentes assaltos realizados por adolescentes, em Natal, especialmente nas feiras livres e nos pontos de ônibus. Era intensa a pressão da sociedade e dos órgãos públicos para a implementação de medidas de repressão contra os 'infratores', e pelo fim do procedimento corriqueiro na Delegacia de Roubos, Furtos e Defraudações - DRFD. Esta era criticada por prender o adolescente e soltá-lo, em seguida, o que ensejava a cultura da impunidade e da desresponsabilização. Por outro lado, eram frequentes as denúncias de desrespeito e violência contra os adolescentes presos, com "problemas de conduta antissocial":

Os que assistiram ao espancamento do jovem prêso (tinha 17 anos de idade) foram unânimes à época, em testemunhar o sadismo e a brutalidade da surra. Geraldo de Souza não apenas utilizava a mangueira de borracha, mas dava murros e pontapés na vítima indefesa, que, a certa altura, pedia até a bênção ao seu algoz, pelo amor de Deus (Tribuna do Norte, 22 de março de 1968).

A Vara de Menores atendia cerca de 20 casos por dia, causando preocupação ao Juizado de Menores. Questionadas sobre a falta de estabelecimentos de internação, ou sobre a paralisação das obras de reforma e construção das unidades previstas, as autoridades alegavam demora no envio de recursos pela FUNABEM. Em junho de 1970, evento denominado "Delinquência juvenil: um problema insolúvel até para o Juiz de Menor", contou com a presença de magistrados de quase todo o estado. Foram discutidos vários projetos, inclusive o da construção de uma Delegacia Especializada de Menores, para evitar o encaminhamento de adolescentes para a DRFD. O Dr. Manoel Araújo afirmou que o judiciário "não tem condições de resolver o problema do menor, já que não se recebe ajuda do estado". Segundo ele, havia dinheiro para tantas obras, mas nunca para a construção de "Reformatório de Menores". Em decorrência da pressão, as obras de algumas instituições foram liberadas em novembro de 1970, com previsão de conclusão para 1972.

O juiz também demonstrou preocupação com o tratamento dispensado, pela polícia, aos adolescentes apreendidos, afirmando que os espancados pioravam ainda mais, porque se sentiam revoltados com a violência. E acrescentou que os adolescentes precisavam de um reformatório, cuja finalidade fosse educá-los, ao invés de ficarem à mercê de policiais que os agrediam. Respondendo ao juiz, a assistente social Giovana Montenegro, representante da FUNABEM no RN, declarou que já havia feito a compra dos equipamentos para o Instituto Estevam Machado, bem como que já estava em construção outra instituição, situada no Morro de Mãe Luiza, bairro da periferia de Natal, até hoje identificado como abrigo de bandidos.

A preocupação com o "adolescente infrator" também foi alvo do "I Encontro sobre o trabalho do menor no Estado", promovido pelo DSSE, em 1970. O Encontro, em que estiveram presentes 54 juízes de todo estado, promotores, assistentes sociais, técnicos e diretores de obras públicas, gerou discussões e encaminhamentos a respeito da defesa dos direitos do adolescente. Dentre os encaminhamentos, destacam-se:

(...) o menor ladrão não deve ser encaminhado ao presídio comum; criação de Unidades Básicas, de âmbito regional para menores delinquentes, abrangendo as Zonas Oeste, Salineira, Seridó e Agreste; criação de Conselhos Municipais na sede das Comarcas; criação de uma Comissão Central de Coordenação das entidades que trabalham com o menor no estado; e criação, na capital, de uma Delegacia Especializada de Menores (Tribuna do Norte, 16 de julho de 1970).

O Encontro também gerou recomendações por parte dos promotores presentes:

(...) mobilizar a comunidade para a criação e desenvolvimento de programas preventivos da delinquência juvenil; que, na recuperação do menor 
delinquente, sejam utilizadas todas as medidas educativas, aplicando-se o internamento, somente nos casos estritamente necessários; promover melhor entrosamento entre a justiça e o organismo social (Tribuna do Norte, 16 de julho de 1970).

Em 19 de setembro de 1976, o Comissário de Menores, Odilon Martins, que atuava na Delegacia de Menores, informou que, até aquela data, já haviam sido registradas 800 queixas por roubos praticados por adolescentes, naquele ano. Segundo ele, cerca de $80 \%$ dos eventos ocorreram em ônibus e a idade média dos "delinquentes" ficava entre 12 e 17 anos. De acordo com o Comissário, a maior parte deles era considerada "irrecuperável", com várias entradas na Delegacia de Menores. Na época, o Instituto Estevam Machado tentava executar um plano de recuperação, mas seus resultados eram considerados incipientes.

Com o objetivo de diminuir o número de assaltos no bairro do Alecrim, onde ainda hoje se realiza a maior feira livre da cidade e onde é marcante o comércio popular, os policiais e investigadores da DRFD passaram a ajudar os investigadores da Delegacia de Menores. Consta que "o combate aos marginais mirins já se fazia necessário devido o número de lances que se vêm verificando, principalmente nas paradas dos coletivos, no interior dos transportes urbanos e nas feiras livres" (A República, agosto de 1977). Em decorrência, começaram as discussões sobre a implantação de uma Subdelegacia de Menores naquele bairro. Luiz Maria Lima, "Delegado de Menores", justificava sua proposta afirmando que, "dos 100 marginais fichados na delegacia, 30\% atuam no bairro do Alecrim", muitos influenciados por criminosos adultos. Seria, assim, descentralizada a ação da Delegacia de Menores, localizada no bairro da Ribeira.

Nesta mesma época o Juiz de Menores, Dr. Manoel Araújo, sinalizou preocupação com a presença de crianças e adolescentes em bares e "casas suspeitas", ou em relação ao fato de andarem em bandos, pelas ruas. Segundo ele, "o que vem mais preocupando o Juizado de Menores, é que várias quadrilhas de adultos vêm usando menores, encaminhando-os para o crime".

Em 1977, o Sr. Otomar Lopes Cardoso, secretário de bem estar social do RN, afirmava que "era necessário fazer muito mais pelo menor desamparado a fim de que o mesmo não viesse a ser um inimigo da sociedade". o depoimento revelava a concepção ainda hoje fortemente presente, de que os "jovens infratores" têm justificada a intervenção do Estado sobre eles, cabendo sua identificação e controle, para não comprometerem o ideal de sociedade e nem o de raça.

Em abril de 1979, foi registrado o espancamento de um adolescente de 16 anos. O jovem foi levado ao Instituto Técnico de Polícia - ITEP -para realização de exame de corpo de delito, quando ficou comprovado o espancamento. As investigações indicaram que o agressor fora Pedro Bezerra, investigador da polícia lotado na Delegacia de Menores. Em decorrência, o juiz da Vara Privativa de Menores, Dr. Manoel Araújo, solicitou do Coronel Bento de Medeiros, chefe da Polinter, a instauração de inquérito policial contra o investigador.

Na segunda metade de 1979, assumiu a Vara de Menores da comarca de Natal, o juiz Carlos Roberto Coelho Maia. Ele visitou os locais de recolhimento de 'adolescentes infratores' e identificou condições físicas insalubres e irregularidades diversas. Por exemplo, observou que adolescentes em situação de abandono eram "misturados" com reincidentes e "marginais famosos", sendo por eles influenciados (A República, 10 de agosto de 1979). Os centros, então especializados na "recuperação" do adolescente "infrator", eram três: Centro de Reeducação do Menor (CRM), antigo Instituto Estevam Machado (IEM); Centro de Recepção e Triagem (CRT); e Instituto Padre João Maria o único destinado a adolescentes do sexo feminino. $O$ juiz, considerando grave a irregularidade observada, solicitou ao Governo do Estado, ao Governo Federal, ao Tribunal de Justiça, à FUNABEM e à Maçonaria que atentassem para o problema, colaborando com recursos financeiros ou outros meios disponíveis.

Outro problema constatado pelo juiz foi a continuação da irregularidade em relação aos apreendidos em flagrante. Ao invés de serem imediatamente levados para a Delegacia de Menores, eram primeiro encaminhados para a DRFD, onde sofriam violência física e psicológica pelos policiais e comissários de menores. Afirmava, o juiz, que faltava material humano com formação adequada para o trabalho com aquele público. Por seu turno, o delegado da DRFD negava quaisquer acusações de violência. Segundo ele, "no caso de resistências por parte do menor, nós deixamos fugir". Também os comissários de menores negavam qualquer tipo de violência, embora considerassem as punições como a melhor forma de tratamento para que os adolescentes se "recuperassem" (Tribuna do Norte, 23 de março de 1980). 
Por outro lado, o juiz foi questionado sobre sua autorização quanto à transferência para a Penitenciária Central, de dois adolescentes que se encontravam no CRM, acusados de latrocínio. Justificou-se dizendo que os jovens haviam se evadido do Centro e praticado roubos e assaltos, sendo necessário transferi-los para um local com mais segurança. Notícia de março de 1980 informava que 63 adolescentes haviam fugido do CRM desde dezembro do ano anterior.

O fato resultou na destituição da diretoria e na indicação de novo comando, a cargo do coronel da Polícia Militar, Durval Barbosa de Siqueira. O novo diretor contestou a reclamação dos internos sobre a qualidade da comida servida no local, afirmando que em casa eles não tinham alimentação semelhante à que era servida no CRM. Sobre as fugas, disse que ocorriam porque o trabalho era realizado em sistema aberto, com os monitores e vigilantes trabalhando sem armas para conter os internos, ficando sob a ameaça dos adolescentes. E que não havia motivo para fugas, pois a unidade oferecia todas as condições para a "recuperação" dos jovens que lá se encontravam: praticavam atividades esportivas e musicais, assistiam tv, tinham oportunidade de realizar passeios durante os finais de semana, além de receberem assistência médica e odontológica. Os "bem comportados" ainda tinham autorização para visitarem os familiares. Na mesma linha, o delegado Luiz Fabrício afirmava que as fugas eram devidas à tentativa de dar um tratamento "humanizado demais para o jovem interno", razão porque a instituição não atingia seus objetivos (Tribuna do Norte, 12 de março de 1980).

De acordo com o Durval Barbosa de Siqueira, os adolescentes que infringiam as normas do Centro eram colocados em celas de isolamento como forma de castigo, onde permaneciam até 24 horas. Contudo, um dos internos afirmou que os castigos duravam até quatro dias. O Coronel ficou na direção do CRM até o ano seguinte, 1981, quando quatro internos se evadiram, cometeram violência sexual contra moradores de uma granja e depois retornaram para a instituição. Com a pressão decorrente do ato infracional grave, o coronel foi exonerado do cargo, em seu lugar assumindo o teólogo Carlos Bompani Neto.

$\mathrm{Na}$ visita que fizera ao sistema de privação de liberdade, o juiz identificou mais um aspecto que feria o Código de Menores de 1979. Era frequente o encaminhamento de adolescentes homicidas para o Complexo Penal João Chaves, destinado a presos comuns, adultos. Havia cerca de 10 adolescentes nesta condição.
O Juizado de Menores recomendou a separação, mas ela não ocorreu, sob a alegação de superlotação no sistema. Há denúncias de que esses adolescentes foram espancados por policiais, dentro do Complexo, como informa a notícia abaixo:

Os delinquentes J. T. N. vulgo Pai Gordo, e S. B. C., de 16 anos, foram espancados, foram torturados dentro da Colônia Penal João Chaves pelos policiais Sargento Tertuliano, sub-tenente Praxedes e os soldados Albuquerque, Manoel, Milton, Albânio e Raimundo, do Corpo de Guarda Penitenciária, em carta-denúncia enviada para a redação da Tribuna do Norte. (...) depois de torturados pelos policiais, foram colocados em uma cela solitária chamada de Lua (...) privados de fazerem suas necessidades fisiológicas em sanitário (Tribuna do Norte, 10 de julho de 1981).

Também foram denunciadas sevícias ocorridas no Centro de Recepções e Triagem (CRT), em crianças e adolescentes que aguardavam uma decisão judicial. Palmatórias de madeira e de borracha faziam parte dos instrumentos utilizados para a "reeducação" dos usuários. Quando brigavam entre si, apanhavam, tinham que assumir a limpeza do prédio e ficavam em isolamento total, inclusive sem comida. Os internos também denunciavam as péssimas condições de funcionamento do local: falta de iluminação nos corredores; falta de alojamentos adequados; total carência de roupas e sandálias. O prédio era a antiga casa de detenção, fechada em face da transferência dos presos para o presídio João Chaves e reaberta, sob promessa de reformas, ainda em 1968, para abrigar o CRT. Uma noção do quadro é dada pelo depoimento abaixo, de uma adolescente de 14 anos:

Na delegacia, eles trata a gente bem, as vez é que dá um puxão de cabelo, que é pra gente se endireitar. Agora, no CRT, eles dão muito nas costas da gente de cassetete e de palmatória de madeira. Os meninos foge porque tem uns que fica querendo agarrar a gente e quando a gente volta, apanha. Eles manda a gente fazer trabalho no sol lá no CRT, eu fico com as mãos e os pés machucado; e depois deixa a gente de castigo, em pé olhando pra parede com os braço aberto. A comida é boa, mas não tem cama pra quem já mora lá, e a gente, que chega, tem que dormir no chão ou nas cama dos outros (Tribuna do Norte, 23 de março de 1980).

Com 68 internos, o Centro era dividido em dois setores: um, para crianças em vulnerabilidade, na faixa de sete aos 12 anos; e outro, para os adolescentes de 
"conduta antissocial" e em conflito com a lei, na faixa entre 13 e 18 anos. $O$ alojamento dos adolescentes tinha apenas cinco camas, para 10 internos. Estes possuíam a farda do colégio, cedida pela FEBEM no início do ano letivo, além de roupas doadas. Embora a diretoria afirmasse não faltar nada para os internos, se registrou a inexistência de roupas para as crianças, as péssimas condições das camas, além da falta de limpeza.

\section{Algumas análises}

Ao atuar na perspectiva da institucionalização de crianças e adolescentes, promovendo, portanto, uma duplicidade contraditória entre salvar e enclausurar, o Estado brasileiro enfatizava o recrudescimento da barbárie envolvendo adolescentes e jovens e repunha a demanda pelo fortalecimento da estrutura penal (Almeida, Soares, Pougy, \& Souza Filho, 2008). Eram notórias as estratégias de punição para o pobre transgressor, justificadas como preventivas em face do crescimento da economia do país.

Em mais da metade do período sobre o qual foi feito o levantamento jornalístico, 1964 a 1988, - Brasil viveu sob a égide da segurança nacional, da ditadura militar. Não obstante, mudanças na política e na nomenclatura das instituições, o quadro não sofreu alterações, a não ser para pior. O caráter autoritário, encarcerador, classista, discriminador e higienista, observado na formulação de 1927 , grosso modo permaneceu intacto (Rizzini, 2008). Avalia-se que era praticamente impossível uma alteração substancial da prática pedagógica com o adolescente institucionalizado. Esta prática era comprometida com uma concepção de desenvolvimento que buscava preservar a criminalização da pobreza, o encarceramento dos adolescentes.

Em decorrência, é emblemático que a imprensa de Natal revelasse, sobre o adolescente em conflito com a lei, os mesmos termos desqualificadores e discriminadores, a mesma concepção individualizante e culpabilizante, fundada em preceitos biológicos e psicanalíticos da adolescência, que se observava nas diretrizes da política nacional. Os jornais revelaram o quanto a realidade local expressava o quadro nacional, inclusive porque o local era regido pelas mesmas leis, contava com semelhantes instituições de atendimento, que visavam o mesmo efeito 'terapêutico' nos 'adolescentes infratores'.

Ademais, o quadro local mostrou a profunda articulação das significações emprestadas pela sociedade civil ao adolescente 'infrator', com as ações das autoridades competentes, no sentido de resolver o problema da perturbação da ordem nas ruas da cidade. Tais ações, inclusive pela representatividade das instituições e das autoridades responsáveis por desencadeá-las, completava o processo por meio do qual eram construídas as significações sociais a respeito daqueles adolescentes pobres, flagrados transgredindo a lei.

Esclarece Duayer (2012), na esteira do pensamento marxiano sobre o trabalho, que,

[...] a prática humano-social é prática teleológica, intencional, finalística, e, por isso, depende crucialmente de uma significação ou figuração do mundo mais ou menos unitária e coerente, não importa se composta por elementos heterogêneos como ciência, religião, pensamento do cotidiano, superstição etc. Em outras palavras, porque a significação do mundo é pressuposto da prática teleológica, é o modo como o mundo é significado que faculta e referenda determinada prática (p. 41).

Nesta direção, é evidente a relação entre os elementos de ordem social, objetivos, e os de ordem pessoal, subjetivos. São os sentidos pessoais, apreendidos dos significados sociais formados cultural e historicamente, que são novamente emprestados aos fenômenos sociais, agora sob a marca do sujeito, da sua significação pessoal. Em outras palavras, a realidade social possui significados construídos ao longo da história, que são interiorizados por cada sujeito. Este significa para si essa realidade e, com base nos sentidos que desenvolve, age e atua novamente sobre a cultura. Em que pese o sujeito agir com base nos sentidos pessoais atribuídos à dinâmica social, tais sentidos obedecem às legalidades sociais, de caráter econômico-político, vigentes em um dado contexto histórico-social.

A esse respeito, afirma Marx (2011) que, "os homens fazem a sua própria história; contudo não a fazem de livre e espontânea vontade, pois não são eles quem escolhem as circunstâncias sob as quais ela é feita, mas estas lhes foram transmitidas assim como se encontram" (p. 25). Na mesma direção, de acordo com Bakhtin (Volochínov, 2006), "a consciência constitui um fato socioideológico [...]", ou melhor dizendo, "os processos que, no essencial, determinam o conteúdo do psiquismo, desenvolvem-se não no organismo, mas fora dele, ainda que o organismo individual participe deles" (p. 49).

Assim, os conteúdos de ordem social que conformam a consciência não são conteúdos quaisquer, descolados da forma de organização do trabalho que 
preside as relações entre os homens, em dado contexto histórico. Nesta direção, os registros jornalísticos tanto davam conta dos sentidos sobre o adolescente 'infrator', formulados por cada um dos diferentes atores do quadro social de Natal, quanto revelavam a trama responsável por constituir as significações sociais das quais se valiam esses atores, para conformarem seus sentidos particulares.

Contudo, na contramão das posturas e das concepções conservadoras e repressoras do Estado e dos cidadãos que agiam em nome dele, observou-se a ampliação das discussões sobre direitos da criança e do adolescente. Aproveitando a conjuntura favorável, ocorreram manifestações populares pelo reordenamento democrático, emergiram novos sujeitos sociais que reivindicavam direitos (Arantes, 2012). A articulação de setores da sociedade civil, em um movimento de defesa da criança e do adolescente, começou a se consolidar neste período. Observou-se iniciativas de afirmação de direitos no próprio espaço governamental e a entrada em cena de novos atores políticos, favoráveis a uma política de assistência e proteção das crianças e adolescentes, condizentes com sua peculiar condição de desenvolvimento (Pinheiro, 2004). Significações contraditórias foram articuladas, sentidos novos foram desenvolvidos.

\section{Considerações finais}

O presente estudo coletou e sistematizou os registros das iniciativas do poder público e as opiniões de alguns dos seus representantes, com vistas ao adolescente pobre, em conflito com a lei, considerado 'infrator'. Inicialmente, configura-se brevemente o quadro nacional das políticas para crianças e adolescentes no Brasil, focando nas proposições e iniciativas que visavam este adolescente. Entende-se que denominá-lo 'infrator' é parte da lógica que preside a política, bem como da orientação que norteia a ação institucional.

Em seguida, apresenta-se o resultado do levantamento documental efetuado nos principais jornais em circulação em Natal, no período entre 1964 e 1988. As notícias mostravam as iniciativas do poder público, bem como as concepções que as orientavam. O intervalo é definido pelo período compreendido entre o início do governo civil-militar e a aprovação da Carta Constitucional, que consolidou a retomada democrática e norteou a nova política para a infância e adolescência no país.
Os dados obtidos foram analisados, primeiro, tendo em vista a articulação do quadro nacional com a realidade local, se observando profunda continuidade entre essas instâncias. Também se apontou os sentidos manifestos pelos atores institucionais a respeito do adolescente objeto das suas ações, e o processo de construção das significações sociais que contribuem decisivamente para tais sentidos. Concluise apontando as contradições sociais que resultaram na redemocratização do país e na promulgação do Estatuto da criança e do adolescente.

Considera-se apenas ensaiada a análise que, partindo de elementos da realidade social e histórica, configura o psiquismo e dirige as ações dos atores sociais. É vasto e múltiplo o material pesquisado, ensejando diferentes estudos que se voltem para a dialética da constituição sentido/significado, na perspectiva do materialismo histórico-dialético e da psicologia históricocultural.

\section{Referências}

Aggio, A.; Barbosa, A. de S.; \& Coelho, H. M. F. (2002). Política e sociedade no Brasil. São Paulo: Annablume.

Almeida, S. S.; Soares, L. T.; Pougy, L. G., \& Souza Filho, R. S. (2008). Da avaliação de programas sociais à construção de políticas públicas: a área da criança e do adolescente. Rio de Janeiro: UFRJ.

Arantes, E. M. de M. (2012). Psicólogos na defensoria pública: olhares da psicologia sobre o direito. Revista da Defensoria Pública. 5(1), 255-260. Recuperado de http://www.defensoria.sp.gov.br/dpesp/ repositorio/20/17artigo.revista2012.pdf

Brasil. (1976). O "menor-problema social" no Brasil e a ação da FUNABEM. Rio de Janeiro: FUNABEM.

Brasil. (1984). FUNABEM, ano 20. Ministério da Previdência e Assistência Social/MPAS. Rio de Janeiro: FUNABEM.

Cavallieri, A. (1976). Direito do menor. Rio de Janeiro: Livraria Freitas Bastos S.A.

Duayer, M. (2012). Marx e a crítica ontológica da sociedade capitalista: crítica do trabalho. Revista Em Pauta, 29(10), 35-47.

Faleiros, V. de P. (2011). Infância e processo político no Brasil. In I. Rizzini \& F. Polotti (Orgs.), A arte de governar crianças. A história das políticas sociais, da legislação e da assistência à infância no Brasil (pp. 97-149). São Paulo: Cortez.

Francischini, R., \& Campos, H. R. (2005). Adolescente em conflito com a lei e medidas socioeducativas: limites e (im)possibilidades. PSICO, Porto Alegre, 36(3), 267-273. Recuperado de http:// revistaseletronicas.pucrs.br/fass/ojs/index.php/revistapsico/article/ view/1397

Gomide, P. I. C. (1990). Menor infrator: a caminho de um novo tempo. Curitiba: Juruá

Lessa, S. (2013). Capital e estado de bem estar: o caráter de classe das políticas públicas. São Paulo: Instituto Lukács.

Marcílio, M. L. (2006). História social da criança abandonada. São Paulo: Aderaldo \& Rothschild 
Martins, J. de S. (1997). Exclusão social e a nova desigualdade (3ª ed.). São Paulo: Paulus.

Marx, K. (2011). O 18 de Brumário de Luís Bonaparte. São Paulo: Boitempo.

Passeti, E. (1987). O que é menor. Coleção Primeiros passos (num. 152, $3^{\text {a }}$ edição). São Paulo. Brasiliense.

Passeti, E. (2009). Crianças carentes e políticas públicas. In História das crianças no Brasil (pp. 347-375). São Paulo: Contexto.

Pinheiro, A. A. A. (2004). A criança e o adolescente, representações sociais e processo constituinte. Psicologia em Estudo, 9(3), 343-355. doi: 10.1590/S1413-73722004000300003
Rizzini, I. (2008). O século perdido. Raízes Históricas das Políticas para a Infância do Brasil. São Paulo: Cortez.

Sales, M. A. (2007). (In)Visibilidade perversa: adolescentes infratores como metáfora da violência. São Paulo: Cortez.

Schneider, L. (1987). Marginalidade e delinquência juvenil. São Paulo Cortez.

Siqueira, L. (1979). Sociologia do direito do menor. Rio de Janeiro: Âmbito Cultural Edições.

Volochínov,V. N.(2006). Marxismo e filosofia da linguagem. São Paulo: Hucitec.

Carmem Plácida Sousa Cavalcante, Mestre em Psicologia pelo Programa de Pós-Graduação em Psicologia da Universidade

Federal do Rio Grande do Norte (UFRN), é Professora da Faculdade de Excelência Educacional do Rio Grande do Norte (FATERN) - Estácio, Natal - RN, e Colaboradora no Centro de Referência em Direitos Humanos da Universidade Federal do Rio Grande do Norte (UFRN).Endereço para correspondência:

Rua Coronel Glicério Cícero - 72. $1^{\circ}$ andar. Bairro Alecrim, Natal/RN. E-mail: carmempscavalcante@gmail.com

Herculano Ricardo Campos, Doutor em Educação pela Universidade Federal do Rio Grande do Norte (UFRN), Pós-Doutor na Universidade Estadual de Maringá, (UEM) é Professor da Universidade Federal do Rio Grande do Norte (UFRN). E-mail: herculanorcampos@gmail.com

Recebido em 23.Abr.15 Revisado em 09.Out.16 Aceito em 22.Nov.16 